\title{
CONSERVACIÓN Y PUESTA EN VALOR DEL YACIMIENTO ARGÁRICO DE CASTELLÓN ALTO (GALERA, GRANADA)
}

\author{
CONSERVATION AND PUBLIC PRESENTATION OF THE ARGARIC SITE \\ OF CASTELLÓN ALTO (GALERA, GRANADA)
}

\author{
M. ${ }^{a}$ OLIVA RODRÍGUEZ-ARIZA (*) \\ EDUARDO FRESNEDA PADILLA $(* *)$ \\ MARCELINO MARTÍN MONTERO (***) \\ FERNANDO MOLINA GONZÁLEZ $(* * * *)$
}

\section{RESUMEN}

La magnífica conservación del registro arqueológico del CastellónAlto permitía reconstruir el urbanismo del poblado y la vida de estas poblaciones. Se han efectuado dos actuaciones con el objetivo principal de facilitar, además de la necesaria conservación, el acceso, la visita y la comprensión del poblado prehistórico por parte de un público mayoritario. La primera actuación se realizó en 1989 y los trabajos se centraron principalmente en la consolidación, restauración y cerramiento del área del yacimiento. La segunda se realizó en 1997 y se centró en el acondicionamiento y reconstrucción de una cabaña y dos sepulturas.

La oferta turística y cultural que ofrece el CastellónAlto se completará con la próxima apertura del MuseoArqueológico de Galera, donde se efectuará una interpretación de este poblado y de la cultura argárica, así como del resto de yacimientos de la zona.

\footnotetext{
ABSTRACT

The magnificent preservation of the archaeological site of CastellonAlto permitted reconstruction of the urbanism of this settlement and the life of its inhabitants. In addition

(*) Centro Andaluz de Arqueología Ibérica. Universidad de Jaén, Edif. B-1. 23071 Jaén. Correo electrónico: moliva@ ujaen.es

(**) Consejería de Cultura de la Junta de Andalucía. Museo Arqueológico y Etnológico Provincial de Granada, Carrera del Darro 43. Granada.

(***) Departamento de Expresión Gráfica en la Arquitectura y en la Ingeniería. Universidad de Granada. Correo electrónico: exprega@azahar.ugr.es

$(* * *)$ Departamento de Prehistoria y Arqueología. Universidad de Granada. Correo electrónico: molinag@platon.ugr.es

El artículo fué remitido en su versión final el 18-IX-2000.
}

to the necessary conservation, two interventions have been carried out with the principal objective of facilitating access, visiting, and the understanding of the site by the majority of the public. The first intervention happened in 1989 and the main task was centered on the consolidation, restoration, and delimiting of the archaeological bed. The second one happened in 1997 and was centered in the consolidation and reconstruction of both a hut and two tombs.

With the opening of the Archaeological Museum of Galera, the cultural and touristic contribution of Castellón Alto will be complete. It will provide an interpretation of this prehistoric village, as well as the Argaric culture in general and all the other archaeological sites of the area.

Palabras clave: Cultura delArgar. Reconstrucción arqueológica. Depresión de Baza.

Key words: Argar Culture. Archaeological reconstruction. Baza Basin.

\section{EL YACIMIENTO}

El Castellón Alto está situado en el término municipal de Galera, a un kilómetro aproximadamente del núcleo urbano, en la margen izquierda del río Galera, dominando una fértil vega, dentro de la depresión de Baza-Huéscar, a $150 \mathrm{Km}$. al norte de la ciudad de Granada. Sus coordenadas geográficas son $37^{\circ} 44^{\prime} 31^{\prime \prime}$ de latitud norte por $2^{\circ} 33^{\prime} 52^{\prime \prime}$ de longitud oeste y su cima alcanza los $900 \mathrm{~m}$ de altura sobre el nivel del mar (Fig. 1).

El poblado se encuadra dentro de la Cultura de E1 Argar, durante un período avanzado del Bronce Pleno (1900-1600 cal ANE), pudiendo sus últimos momentos adscribirse al Bronce Tardío. 


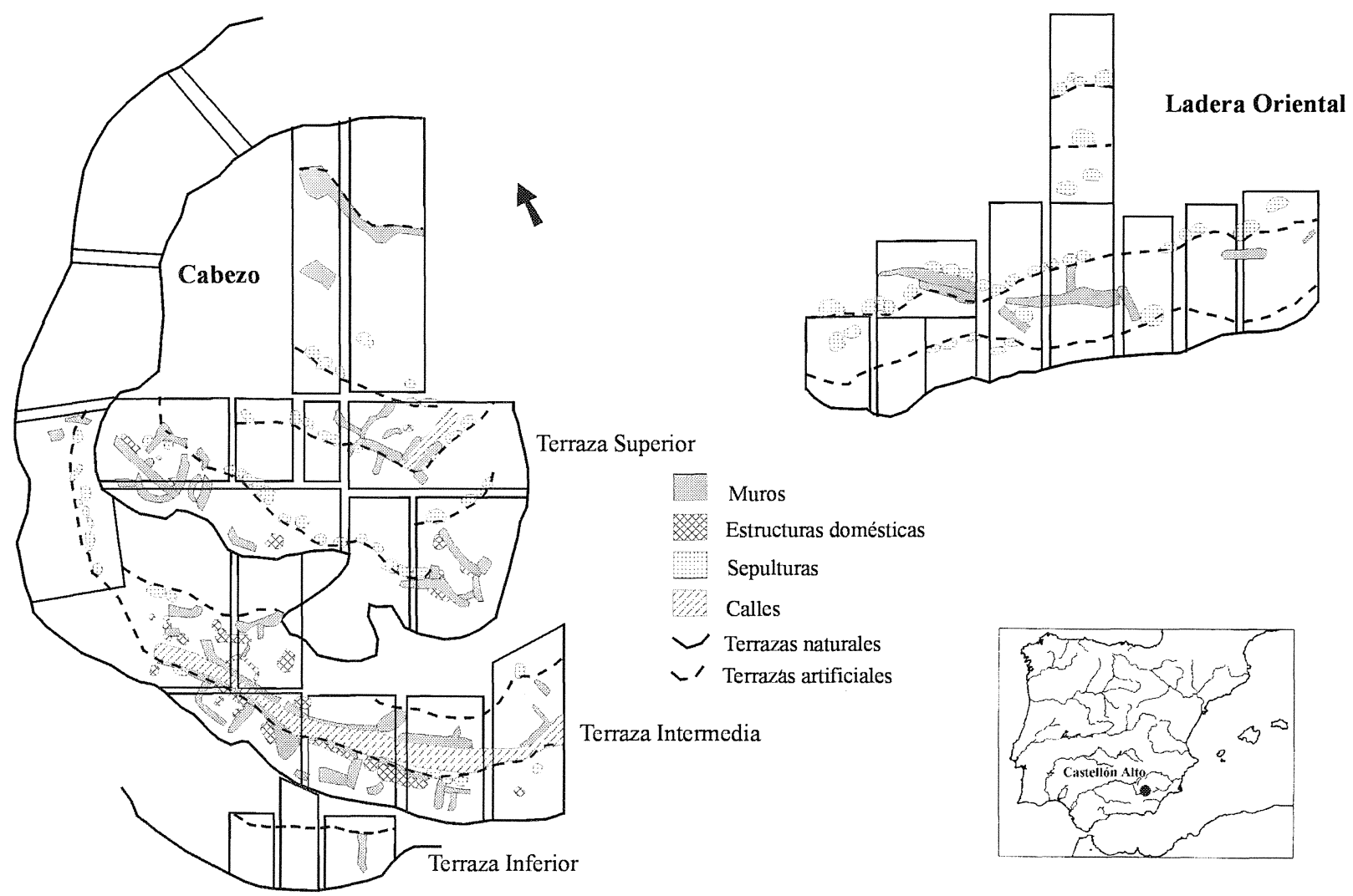

Fig. 1. Situación del CastellónAlto (Galera, Granada) y planta general esquemática del área excavada con la ubicación de los cortes.

El yacimiento se emplaza sobre un espolón que se destaca de los cerros colindantes y desde el que se domina una amplia extensión de terreno, extendiéndose también hacia la ladera del cerro contiguo (Lám. I). El CastellónAlto posee una serie de terrazas naturales en las que se situó el poblado, adaptándose a la configuración del terreno (Fig. 1). Un profundo barranco deja perfectamente delimitado el yacimiento hacia el sur, separándolo de un asentamiento más antiguo, de la Edad del Cobre, que se asienta sobre dos lomas más suaves. El yacimiento descansa sobre una antigua mina de yeso que hace que el cerro sobre el que se asienta esté totalmente hueco (Lám. I), lo que provoca la apertura de grietas en la superficie de la zona arqueológica. Esta original disposición junto a la frágil geología del lugar (yesos y margas) hacen que los problemas de conservación del lugar sean muy particulares y específicos, difícilmente referibles en cualquier otro lugar arqueológico.

El Departamento de Prehistoria y Arqueología de la Universidad de Granada realizó dos campa- ñas de excavación prácticamente seguidas en 1983 (junio-julio y septiembre-noviembre) (Molina $e t$ alii, 1986). Los trabajos de excavación permitieron obtener una importante documentación arqueológica sobre todos los aspectos del urbanismo, economía, rituales funerarios, etc. que brevemente resumimos.

El hábitat se sitúa en dos grandes unidades (Fig. 1) conectadas entre sí: el cabezo o espolón con sus tres terrazas naturales (Superior, Intermedia e Inferior) y la ladera oriental del cerro contiguo. En dichas terrazas naturales y laderas, separadas por altos escarpes, se procedió a cortar la roca virgen de forma artificial, construyendo diversas plataformas horizontales y escalonadas, que convierten la mayor parte del cerro en área habitable. Sobre estos aterrazamientos artificiales se situaron las viviendas, edificadas con un muro posterior que reviste la pared rocosa a todo lo largo de la terraza y otro muro delantero, paralelo al anterior, que configura un espacio rectangular, compartimentado por finos tabiques transversales formados por un entramado 


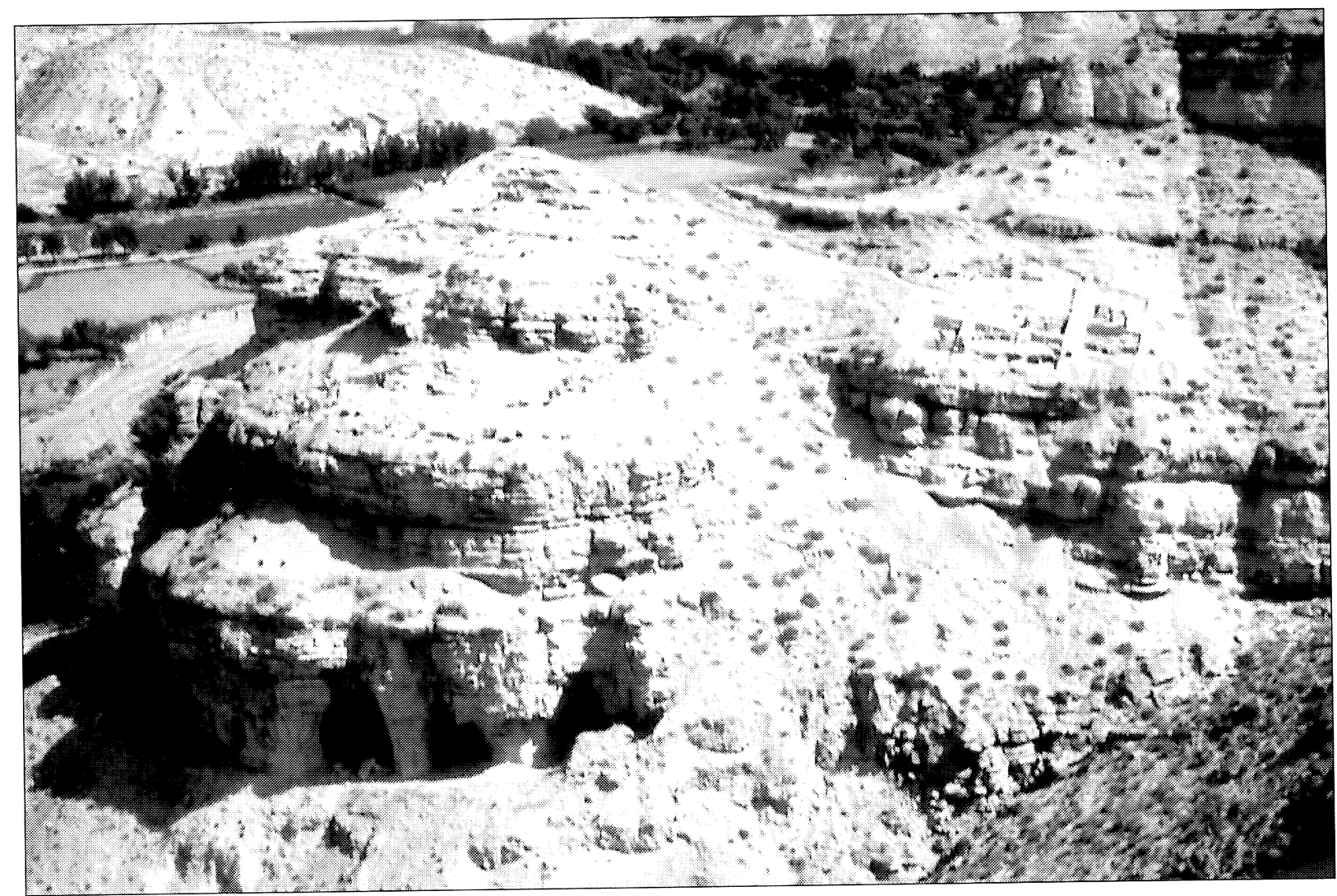

Lám. I. Castellón Alto (Galera, Granada). Vista general del asentamiento sobre la vega del Río Castilléjar.

de barro y cañas o por muros de mampostería de mayor envergadura. En algunas ocasiones, las habitaciones, para adaptarse al terreno, ofrecen plantas poligonales. El acceso a las viviendas se realiza a través de escaleras, que conectan las terrazas, y estrechas calles, así como, posiblemente, por los techos planos de algunas viviendas.

Se han documentado tres fases constructivas del poblado: la primera, extendida por toda la superficie del cerro, termina con un incendio generalizado, tras el cual se realizan una serie de reorganizaciones de viviendas y en el sector oeste de la terraza intermedia se crea un espacio que debió utilizarse como establo. Esta segunda fase también termina con un incendio, tras el cual el hábitat sólo se reconstruye en zonas puntuales. La mayoría de las unidades habitacionales del poblado tienen una o dos sepulturas en su interior. Se han documentado más de un centenar, de ellas una cuarentena violadas por excavadores clandestinos. Las sepulturas, salvo las inhumaciones infantiles en urna, son covachas artificiales excavadas en roca, que en ocasiones se abren lateralmente a la base de una fosa vertical y fosas simples. Las covachas están selladas en su mayoría por grandes losas que se calzan con piedras y a veces se les antepone un murete de piedras trabajado con yeso (Lám. II) y, en ocasiones, tablas de madera que sustituyen a las losas de piedra.

La presencia de 16 sepulturas con inhumación doble, dos con triple, una cuádruple y otra quíntuple, nos revela las importantes relaciones familiares, máxime cuando 11 de estas sepulturas son de parejas de hombre-mujer, indicando la importancia de los vínculos matrimoniales y el papel que jugaría dentro de la adquisición de estatus dentro de la comunidad. Se puede aventurar que existe cierta diferencia en la composición de los ajuares por sexos. En las tumbas masculinas son típicas las hojas de puñal, hachas de cobre y los vasos carenados de cerámica, apareciendo las copas asociadas a individuos de mayor estatus. En los enterramientos femeninos son corrientes, por el contrario, punzones de cobre y hueso, y entre la cerámica ollas y cuencos, apareciendo también las copas en ajuares de mayor entidad. Ambos sexos presentan adornos 


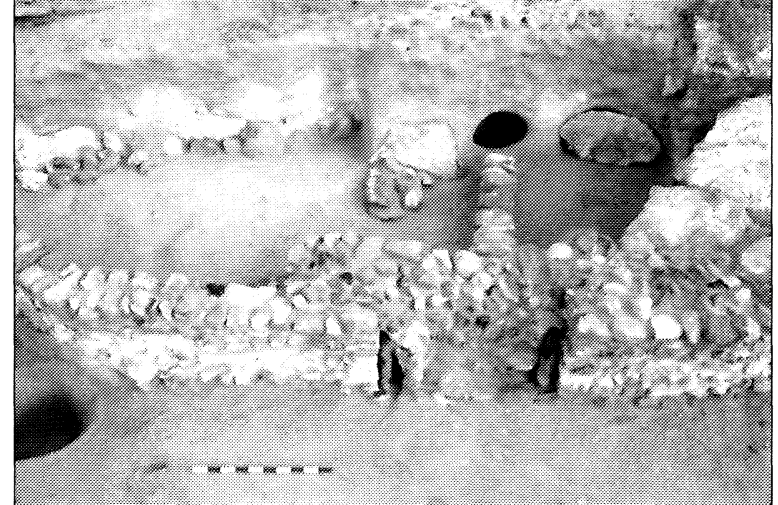

A

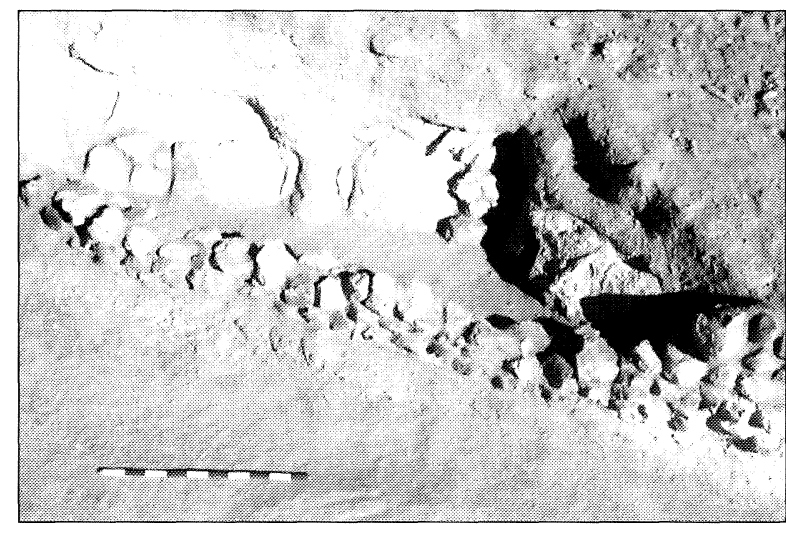

B

Lám. II. CastellónAlto (Galera, Granada). Sepulturas restauradas. A) Terraza Inferior de la Ladera Oriental tras su restauración en 1989. B) Sepulturas 36, 37 y 38 de la Ladera Oriental con sus losas de cierre.

personales como collares, pendientes y pulseras.

La magnífica conservación del registro arqueológico del CastellónAlto, especialmente los restos orgánicos, ha permitido obtener una importante conocimiento no sólo del medio ambiente de la época y su explotación económica (Rodríguez-Ariza et alii, 1996, Rodríguez-Ariza y Ruiz, 1995), sino también de las bases tecnológicas de esta comunidad, analizando las principales manufacturas que tenían lugar en el poblado, desde la fabricación de los vasos cerámicos hasta el trabajo de la piedra, hueso y materias orgánicas como el esparto, el lino o la lana (Contreras et alii, 1997).

Por tanto, los resultados obtenidos nos han permitido poder reconstruir el urbanismo de este asentamiento y la vida cotidiana de su población. Asimismo, por su situación sobre el río Galera (Lám. I), el yacimiento domina un amplio territorio, constituyendo una magnífica ventana a un ecosistema con una personalidad muy acusada, donde se desarrollan especies vegetales únicas, características de medios áridos y yesosos, junto a una agricultura tradicional de regadío. Siendo conscientes de la oportunidad que ofrece este yacimiento arqueológico para la puesta en valor de lo recuperado, ofreciendo una lectura contextualizada de los diferentes elementos, el Departamento de Prehistoria yArqueología de la Universidad de Granada promueve los trabajos de consolidación, restauración y acondicionamiento del mismo, trabajos que se realizan en 1989. En marzo de 1996, como reconocimiento de sus aportaciones para el estudio de la Edad del Bronce y de la Cultura argárica, el Castellón Alto fue declarado Bien de Interés Cultural. Entre Noviembre de 1997 y marzo de 1998 se realiza una exposición sobre los yacimientos de Peñalosa y Castellón Alto en las ciudades de Granada y Jaén (Contreras et alii, 1997), que supone una concienciación de la población de Galera sobre el valor de su patrimonio arqueólógico. A partir de este momento un grupo de jóvenes del pueblo se encarga del control de la visita. En la localidad de Galera se está construyendo un MuseoArqueológico, promovido por su Ayuntamiento, el cual servirá de centro de interpretación del Castellón Alto y del resto de yacimientos del municipio (Tútugi, Cerro del Real, FuenteAmarga, etc.).

\section{LA ACTUACIÓN DE 1989}

Los trabajos de consolidación, restauración y acondicionamiento del CastellónAlto se realizaron entre el 15 de junio y el 20 de noviembre de 1989. El proyecto de actuación y dirección de los trabajos fueron realizados por Marcelino Martín, como arquitecto, Eduardo Fresneda y Fernando Molina, como arqueólogos, y $\mathrm{M}^{\mathrm{a}}$ Oliva Rodríguez llevó la dirección técnica de todos los trabajos. La actuación fue subvencionada por la Consejería de Cultura de la Junta de Andalucía.

En el Proyecto de restauración y acondicionamiento del CastellónAlto se contempló un apartado de excavación, con su correspondiente presupuesto. La excavación se planteó como apoyo a la restauración, con el objetivo básico de ampliar la zona de visita y ofrecer una visión más global del espacio en las diversas zonas del asentamiento, así como resolver algunos problemas de interpretación de los replanteamientos del hábitat a lo largo de las tres fases estratigráficas. 


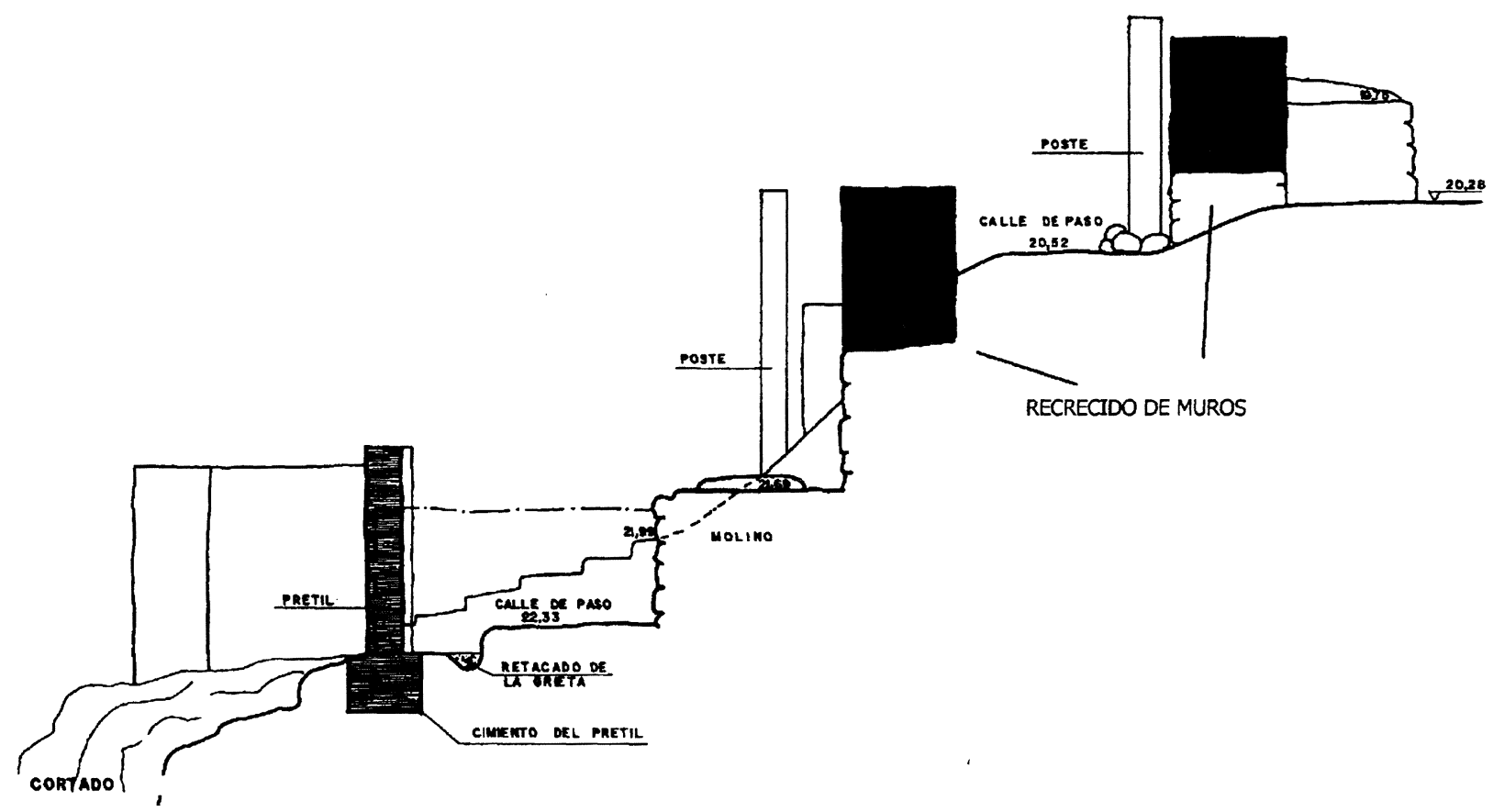

Fig. 2. Castellón Alto (Galera, Granada). Sección de la Terraza Intermedia del Cabezo con las actuaciones realizadas.

Los trabajos se centraron principalmente en la consolidación, restauración y cerramiento del área del yacimiento. El objetivo principal de la actuación era facilitar, además de la necesaria conservación, el acceso, la visita y la comprensión del poblado prehistórico. Por ello, no se actuó en todo el yacimiento, sino en aquellas áreas que contaban con una mayor superficie excavada y que podían ofrecernos una visión lo más completa y comprensible sobre el urbanismo, la disposición interna de las viviendas y las sepulturas.

La zona donde más se incidió fué la Terraza Intermedia del Cabezo, donde se conservan viviendas, separadas por una calle, con muros originales de más de 1,50 m de altura (Fig. 2). Por el contrario en varias zonas del yacimiento no se ha actuado, dejandolas cerradas al público, a la espera de una futura intervención que complete la puesta en valor del CastellónAlto. Este es el caso de la Terraza Inferior, con un acceso difícil y excavada sólo superficialmente, y del Sector occidental de la Terraza Intermedia ambas en el Cabezo y de las Terrazas Superior e Intermedia de la Ladera.

Se describen a continuación cada una de las actuaciones realizadas:

- Aparcamiento. En la base de la senda de acceso al yacimiento el Ayuntamiento de Galera compró una parcela para la realización de un aparca- miento. Se realizó una gran explanada allanando la parte baja del terreno, mediante la excavación y realización de taludes. El suelo se compactó con zahorra y grava traída del exterior. También se realizó una zanja por encima de los taludes para el desvío de las aguas pluviales.

- Senda de acceso. Se efectuó un terraplenado para la ampliación del ancho y mejora del perfil longitudinal y transversal. Para ello se tuvieron que realizar varios muros de piedra seca para la contención de las tierras en las zonas con una topografía más abrupta. El suelo, al igual que el aparcamiento, se mejoró con aportes de grava, zahorra y compactación. Con los trabajos realizados la estrecha vereda se ha transformado en un camino de acceso peatonal.

- Cerca. Para el cerramiento del yacimiento por la zona norte se ha elegido la malla electrosoldada, adaptada a la pendiente del terreno con un perfil en catenaria. Esta permite la visión a su través lo que, junto su color pardo amarillento similar al del terreno, facilita su integración con el entorno.

La rigidez se consigue mediante ángulos perimetrales de acero que sirven de marco a cada paño de $2 \mathrm{~m}$ en los que se subdivide el conjunto. La estabilidad y anclaje al suelo se realiza mediante el embebido de los angulares verticales en el murete de hormigón en masa, que sirve de cimiento y que al 


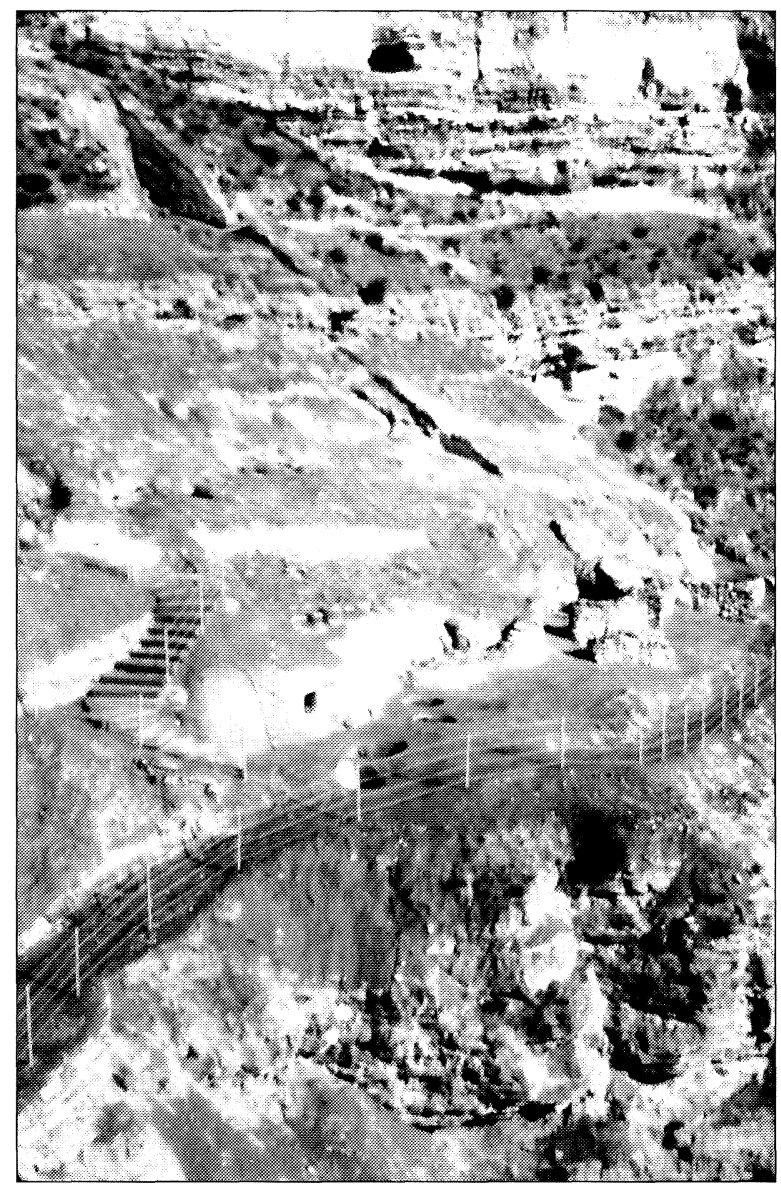

Lám. III. CastellónAlto (Galera, Granada). Vista general de la Ladera Oriental desde la Terraza Superior del Cabezo o Espolón.

sobresalir del terreno unos $50 \mathrm{~cm}$ permite su utilización como ligera contención de las tierras, lo que posibilita la explanación de la zona de acogida.

Uno de los paños es abatible y permite el acceso, cerrándose mediante candado.

- Zona de acogida. Junto a la puerta de acceso, en una zona sin restos arqueológicos, se ha explanado una pequeña área. En ella se ha colocado un plano xerografiado del yacimiento, en colores y con leyenda, inserto en soporte metálico de suficiente rigidez para soportar la climatología del lugar y su situación expuesta. Esta área sirve de zona de acogida a los visitantes y, por su situación sobre parte del poblado, permite recibir las primeras explicaciones sobre la ubicación y urbanismo del mismo.

- Itinerarios. Desde el lugar anterior se inician los recorridos por el yacimiento con dos posibles alternativas: ascender y luego descender por la Terraza Superior o descender hasta la Ladera Oriental. La abrupta topografía del lugar, con fuertes desniveles entre terrazas y zonas del poblado, ha exigido que para la realización de los caminos se ejecutaran varias obras de acondicionamiento con más o menos grado de intervención:

- para salvar el desnivel entre terrazas se han realizado escalinatas. En zonas exentas de estructuras arqueológicas se ha optado por el hormigón en masa, caso del acceso a la Ladera Oriental (Lám. III) y de las escaleras entre la Terraza Superior e Intermedia, y en aquellas zonas donde quedaban restos originales de escaleras (zona junto a la vivienda reconstruida) o posibilidad de utilizar parcial o completamente el propio terreno (corte 35 de la Terraza Intermedia, acceso a la zona inferior de la Terraza Intermedia) se han consolidado o reconstruido con piedras, para integrarlas en el contexto arqueológico;

- por las características del poblado, situado en un espolón sobre el valle con fuertes escarpes de varios metros de altura, se hacía necesario realizar protecciones que aseguraran una seguridad en el recorrido. Así, en las Terrazas Intermedia y Superior donde las estructuras arqueológicas están próximas a los cortados y, por tanto, el recorrido se realiza junto a estos, se han realizado pretiles constituídos por tres cables trenzados y tensados que atraviesan tubos verticales de acero galvanizado, insertos en muretes de hormigón en masa empotrados en el terreno (Lám. IV). Estos muretes y las protecciones se acomodan al perfil del terreno en cada lugar, excluyendo las nivelaciones. En las zonas donde existe suficiente espacio para la circulación de personas y el cortado está un poco separado, caso de la Ladera Oriental y de los accesos a ésta, se ha optado por realizar una protección a base de cables trenzados, aunque sin pretil de hormigón.

Los elementos metálicos (tubos y cables) se han pintado con un color amarillo claro similar al tono medio del terreno natural buscando su mejor integración en el mismo. Igual intento ha sido la elección del tipo de protección, sencilla y firme, creando la menor ruptura posible con el medio circundante.

Tan sólo en un lugar, delante de la vivienda restaurada, se ha restituido un auténtico pretil de fábrica de piedra, en el lugar donde se documentó su existencia (Lam.V).

- Drenaje de aguas pluviales. La evacuación de las aguas que se recogen en las viviendas restauradas, que con el recrecido de los muros no tienen salida, se ha realizado mediante tuberías de PVC, 


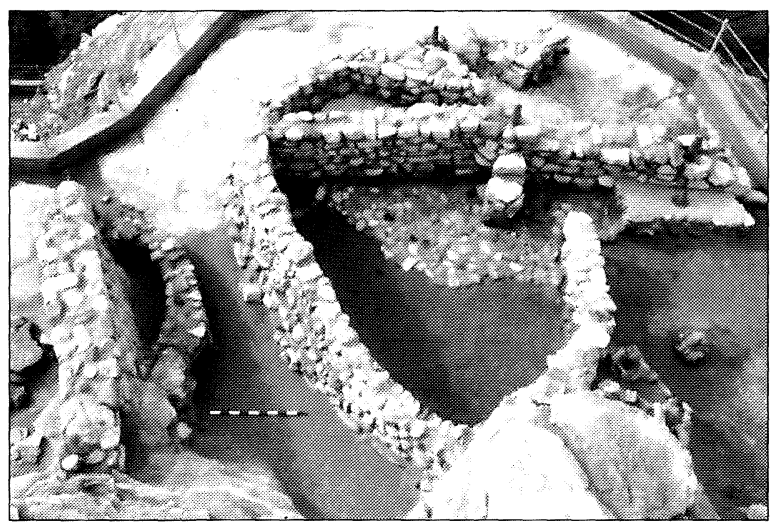

A

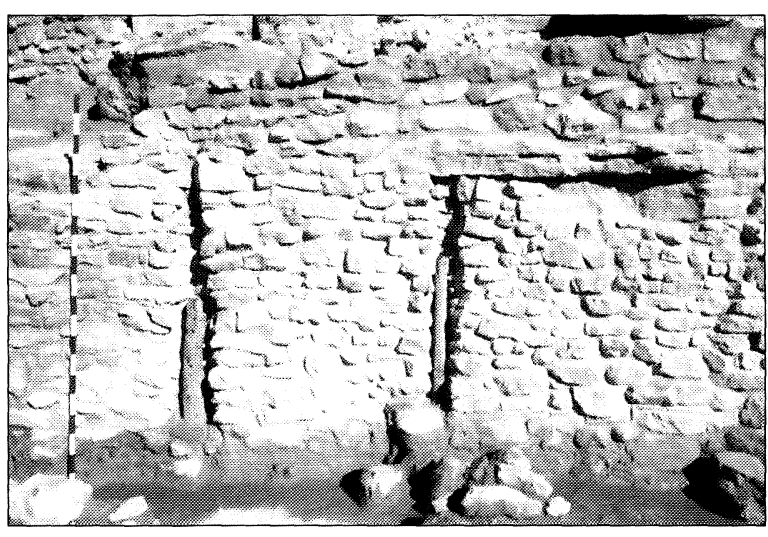

B

Lám. IV. CastellónAlto (Galera, Granada).A) Sector Oeste de la Terraza Superior tras su restauración. B) Muro posterior de la vivienda del Corte 14 con el paramento reconstruido.

enterradas bajo drenaje de grava y terreno natural. En algunos casos, se han aprovechado las grietas naturales del terreno, antes de su colmatación, para insertar las tuberías que vierten a las vaguadas y a los cortados. También se han realizado pasos a través de los pretiles de protección. Para evitar las arroyadas que afectaban a las estructuras arqueológicas de la Ladera Oriental se realizó una zanja por encima de toda la zona restaurada que, en caso de lluvia, desvía el agua hacia el barranco.

- Colmatación de grietas. La geología del lugar compuesta por niveles de areniscas, yesos y gredas, materiales frágiles y fácilmente erosionables por agentes atmosféricos como la lluvia, hacen que existan numerosas grietas en el poblado. Las existentes en la zona restaurada fueron colmatadas mediante vertido de mezclas de mortero con granulometría variable, acomodando la parte superior a la textura de la zona.
- Consolidación y realzado de muros. Las estructuras murarias exhumadas en el transcurso de la excavación presentan diversos niveles de conservación dependiendo de la zona del yacimiento: en la Terraza Superior y en la Ladera Oriental las estructuras murarias están incompletas por efecto de la fuerte erosión y de las propias remodelaciones del poblado (Lám. IVA); sin embargo, en la Terraza Intermedia existen muros de $1,50 \mathrm{~m}$ de altura y casas de trazado completo (Lám.V). Este hecho impuso que se realizara, por un lado, una consolidación de las estructuras en buen estado, limpiando las oquedades internas y espacios entre piedras de tierra e inyectandole argamasa con cemento PY como aglomerante, para la parte externa con el fin de adecuarlas a su aspecto original. Después de diversas pruebas de morteros, se optó por una mezcla de tierra del lugar con látex al 50\% y sikament, plastocrete y agua al 16,6\% respectivamente. Las estructuras más incompletas se realzaron en una o dos hiladas de piedras, colócándose una fina línea de baldosas cerámicas de color rojo entre la zona original y la restaurada (Lám. V B). Igualmente los frentes y coronaciones de muros fueron recubiertos con la mezcla anterior de tierra y resinas para unificar el aspecto general.

- Reconstrucción y consolidación de cortes de terrazas. Debido a las características del terreno, de gran fragilidad ante la erosión, parte de los frentes de las terrazas después de ser excavadas sufrieron algunos deterioros. Para dar estabilidad al terreno e impedir que la erosión siguiera actuando en dichas áreas se reforzaron y consolidaron los bordes de algunas terrazas. En la Ladera Oriental y en la Terraza Superior se reconstruyeron varios frentes mediante muros de piedra con argamasa de hormigón, que fueron recubiertos externamente con la mezcla de tierra y resinas utilizada en los muros, con el fin de mimetizarlos con el entorno natural del yacimiento (Lám. II).

- Reconstrucción y restauración de tumbas. En el poblado se han documentado tres tipos de sepulturas: en tinajas o pithoi, utilizadas sólo para enterramientos infantiles, en covachas bajo las paredes interiores de las viviendas y en fosas bajo los pavimentos. Son las covachas las más numerosas y, por tanto, sobre las que se ha actuado preferentemente. La mayoría de ellas estaban afectadas por la erosión y la propia composición del terreno a base de gredas, que al abrir las sepulturas sufren un proceso de secado, provocando desprendimientos inmediatos del techo y las paredes. 


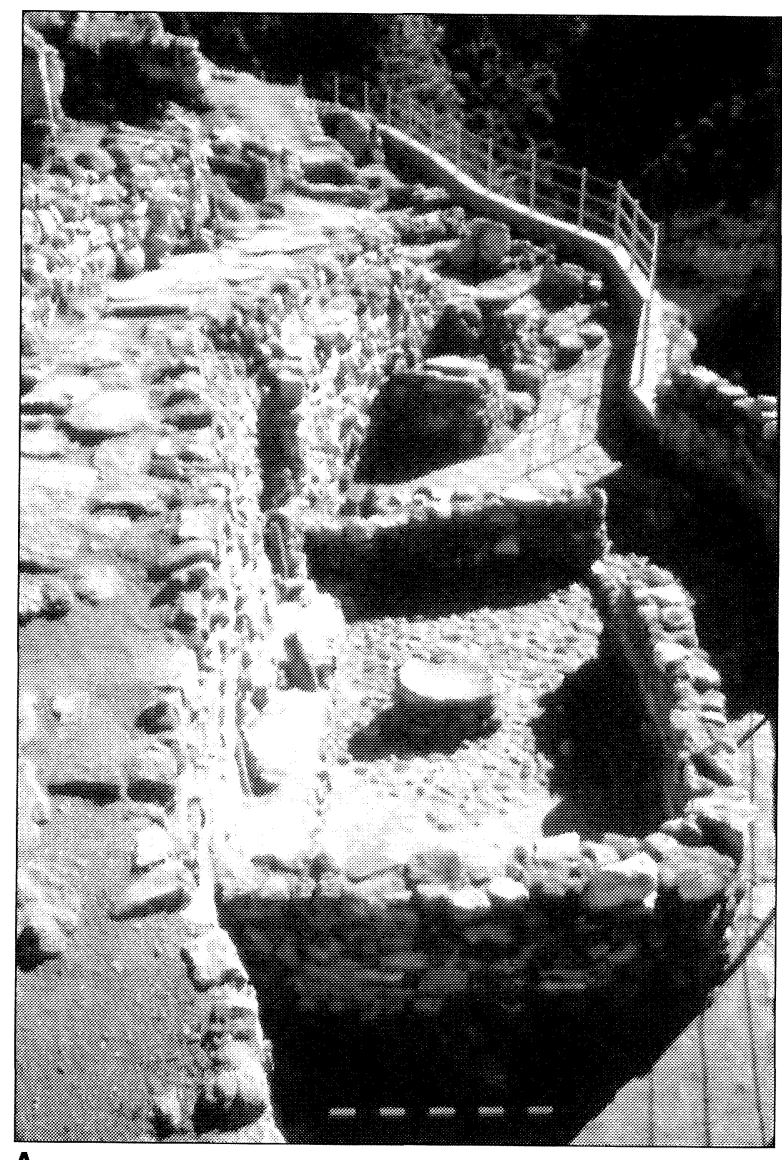

A

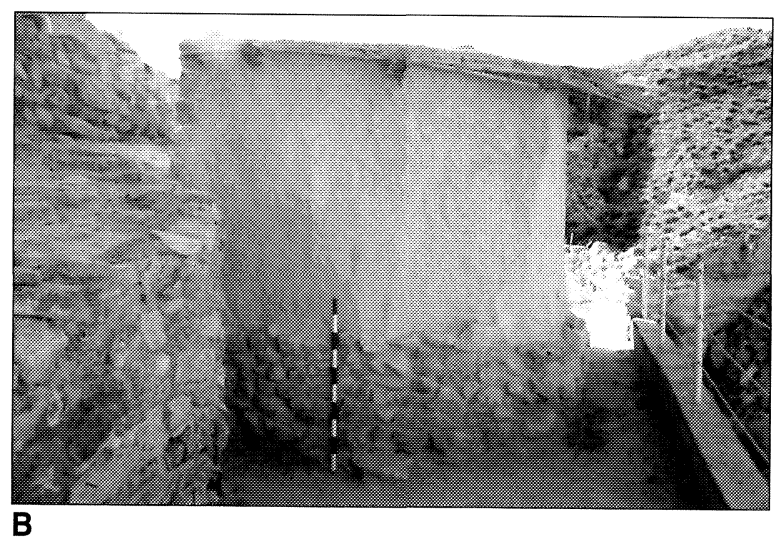

Lám. V. Castellón Alto (Galera, Granada). Vivienda del corte 13: A) tras su consolidación y restauración en 1989; B) aspecto exterior tras su reconstrucción en 1997.

Para la reconstrucción de las bóvedas se ha utilizado la rasilla cerámica que fue totalmente disimulada con un enfoscado de mortero realizado con tierra del lugar, lo que le da un aspecto muy parecido al natural (Lám. VI). Muchas de estas covachas han sido cerradas con las piedras originales de cerramiento, principalmente lajas que habían sido numeradas en la campaña de excavación, dejando otras abiertas para que se vea su estructura interna (Lám. II).

- Reconstrucción de pavimentos. Los suelos de algunas viviendas estaban realizados por un empedrado de piedras pequeñas y medianas, al que se superpone una capa de tierra de color blanquecino que creaba un pavimento más o menos uniforme. Se han restaurado los pavimentos de las viviendas del corte 13 (Lám. V A) en la Terraza Intermedia y la del Corte 34 (Lám. IVA) de la Terraza Superior, dejando una parte con el empedrado visto y otra con una lechada de mortero que lo recubre, siempre con el objeto de que se pueda observar la técnica de construcción.

La calle que recorre la Terraza Intermedia en su sector más occidental se reconstruyó a base de grandes losas, según la documentación obtenida en su excavación.

- Colocación de postes de madera. En los trabajos de excavación del yacimiento se pudieron documentar una gran cantidad de hoyos de poste que mantenían aún en su interior los restos de la madera. Estos postes, que sostenían la cubierta o formaban las jambas de las puertas de las viviendas, eran de pino carrasco. Gracias a la colaboración de la Delegación de Medio Ambiente de la Junta de Andalucía pudimos obtener troncos de pinos. Estos se cortaron en fragmentos de menos de un metro, los que fueron quemados por uno de sus extremos, para que tuvieran el aspecto similar al de los originales. Posteriormente se consolidaron con varias capas de paraloid para darle consistencia frente a los agentes atmosféricos. Su colocación en varias zonas del poblado, siempre reemplazando a los originales, permite explicar el sistema de construcción de las viviendas.

- Restauración de estructuras domésticas. Dentro de las cabañas se han restaurado algunos de los elementos constitutivos de éstas como bancos de piedra corridos, molinos y hogares (Láms. IV, V). Las piedras de molino en el interior de las viviendas aparecían sobre una pequeña base de piedra que los sostiene y eleva para facilitar la molienda. Estas estructuras se han consolidado en casi todas las viviendas, así como la del gran molino existente en la Terraza Intermedia (Fig. 2). Igualmente, todas las viviendas disponían de un hogar, generalmente, con una estructura circular muy sencilla realizada con piedras, que en su mayoría se han 

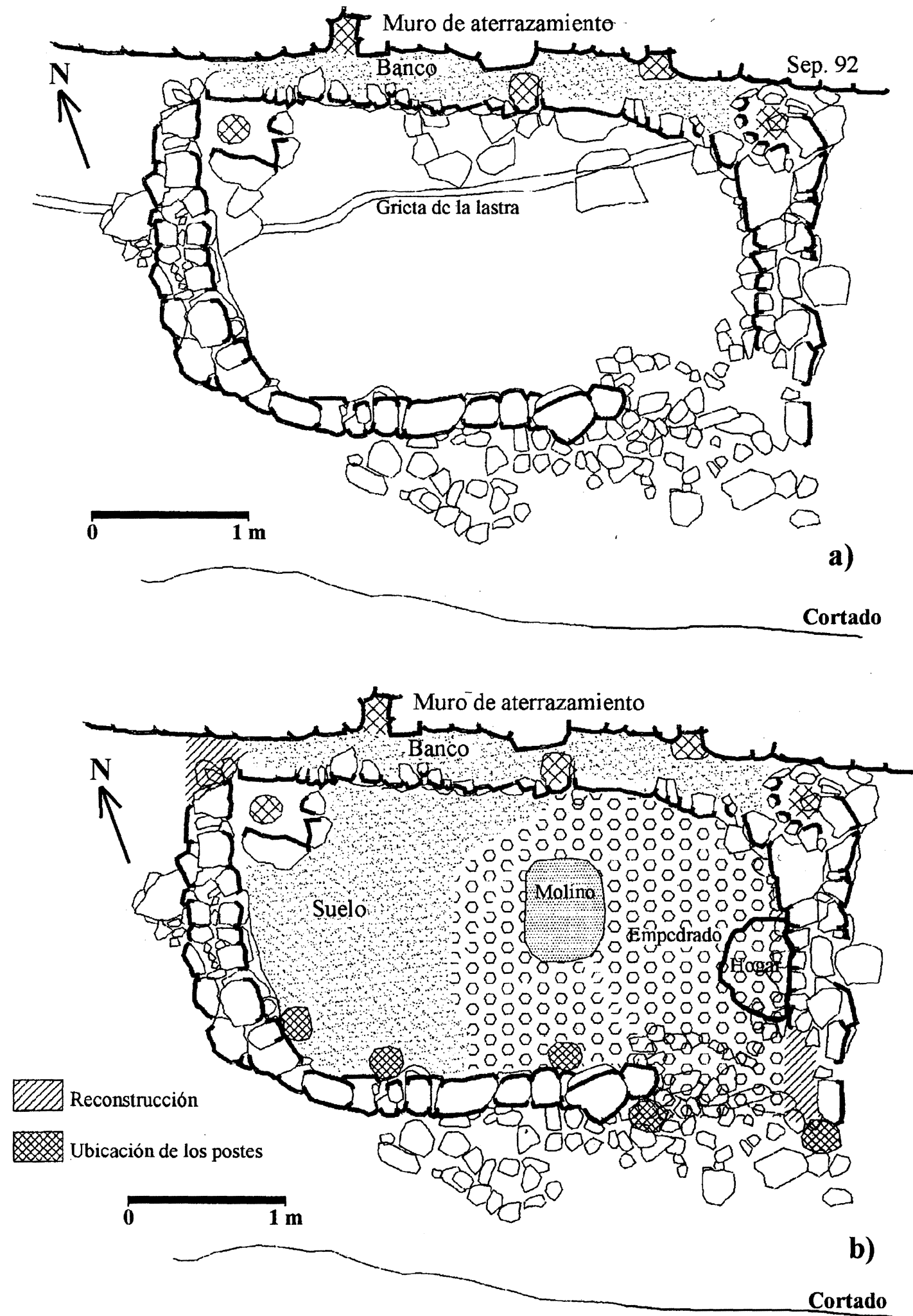

Fig. 3. Castellón Alto (Galera, Granada). Planta de la Vivienda restaurada y reconstruida de la Terraza Intermedia: a) tras su excavación, b) tras su consolidación y restauración.

T. P., 57, n. $^{\circ} 2,2000$ 
restaurado y, en algunos casos, se han rellenado con tierra y restos de fuegos (carbón y cenizas) para hacerlos más comprensibles.

\section{ACTUACIÓN DE 1997}

Dentro del Campo de Trabajo Galera Argárica "vive tus orígenes" patrocinado por la Dirección General de Juventud de la Junta de Andalucía y promovido por el Colectivo Juvenil Natura-Gale$r a$, se realizaron trabajos de limpieza, complementándose con el acondicionamiento y restauración integral de una vivienda y dos sepulturas. Los trabajos fueron dirigidos por $\mathrm{M}^{\mathrm{a}}$ Oliva RodríguezAriza.

- Reconstrucción de una habitación de la Vivienda del corte 13. La habitación principal de la Vivienda del corte 13 tiene planta rectangular (Fig. 3 ). Fue construida con un zócalo de piedras, el cual está restaurado en su totalidad. Existe un banco corrido junto al muro de aterrazamiento, recubierto por una capa de adobe rojizo. También han aparecido cinco hoyos de poste en las esquinas y en el banco, que formarían parte de la estructura de sostén del techo de la vivienda. Uno de ellos, localizado en la esquina suroriental, era una reutilización de un enterramiento infantil (Sep. 92). El suelo se realizó con una capa de barro rojizo, asentada sobre un lecho de piedras pequeñas que servían para nivelar la superficie. La entrada se encuentra en la esquina suroriental y consta de un vano, al cual se accede por un pequeño escalón, junto a éste se encuentran dos hoyos de los postes que sostendrían la puerta o estera.

Los trabajos de reconstrucción de la cabaña se han realizado siguiendo el siguiente esquema:

- Transporte de los postes, vigas y travesaños de pino. Para la realización de la estructura de la cabaña hemos contado con pinos silvestres procedentes de la Sierra de Baza, proporcionados por la Delegación Provincial de la Consejería deAgricultura de la Junta deAndalucía. Los ejemplares proporcionados eran de dos medidas: unos de gran porte (15$25 \mathrm{~cm}$ de grosor y 2-3 $\mathrm{m}$ de largo), que han sido utilizados como postes, y otros más pequeños (entre $4-10 \mathrm{~cm}$ y $1-1,4 \mathrm{~m}$ de largo) que hemos utilizado como travesaños.

- Nivelación y corte de los postes. Una vez ubicados de forma provisional los postes, se procedió a la nivelación de todos ellos, dando a los cinco junto al muro de aterrazamiento $10 \mathrm{~cm}$ más de al- tura que a los cinco delanteros, con el fin de crear un pequeño desnivel en el techo. La parte sobrante de los postes fué cortada con una sierra manual. También se realizaron muescas en forma de $\mathrm{V}$ en la parte superior de todos los postes para la colocación y encaje de la vigas.

- Ubicación y realización de los hoyos de postes. Hemos seguido el modelo que se repite en el yacimiento, que consiste en la apertura de un hoyo en el que se ubica el poste y se calza con piedras pequeñas alrededor. A fin de dar mayor consistencia a los postes, éstos se cogieron con yeso y piedras, disimulando posteriormente el yeso con una mezcla de barro con Primal AC33.

- Construcción del armazón de vigas. Se instalaron las vigas sobre las muescas realizadas a los postes delanteros y traseros de la vivienda, se unieron posteriormente a éstos con cuerdas de esparto. Las cuerdas de esparto han sido realizadas por un vecino de Galera, de forma desinteresada, siguiendo los modelos documentados en el transcurso de la excavación.

- Colocación de los travesaños. Sobre las vigas y en sentido perpendicular a éstas se han colocado los travesaños de pino, con una distancia aproximada de unos 60-70 cm, con lo cual se han obtenido unas 3 ó 4 líneas, formando un entramado entre los postes, vigas y travesaños de gran consistencia, preparado para el cierre del techo. Estos travesaños se han unido, igualmente, a las vigas con cuerdas de esparto (Fig. 4).

- Tratamiento de la madera. Antes de la colocación de los postes y vigas se procedió a dar a la madera varias capas de paraloid, operación que fue repetida una vez formado el armazón general de la vivienda. Con este tratamiento se pretende preservar a la madera de los agentes atmosféricos y evitar el deterioro. En 1989 los postes quemados que se dejaron colocados por todo el yacimiento fueron tratados con este mismo producto, presentando en la actualidad un buen estado de conservación.

- Realización de las paredes laterales. En el transcurso de la excavación se pudo documentar en varias zonas del poblado la existencia de improntas de cañas en trozos de barro, que formaban parte de las paredes de las casas. Por tanto, se ha realizado un entramado de cañas que se alzó sobre los muros de piedras (Fig. 4). Para que este entramado tuviera mayor sujeción se realizó con anterioridad a la techumbre, de modo que las cañas de las paredes y del techo se trabaran entre si y formara un bloque consistente. Este entramado se ha cubierto con

T. P., 57, n. $^{\circ} 2,2000$ 


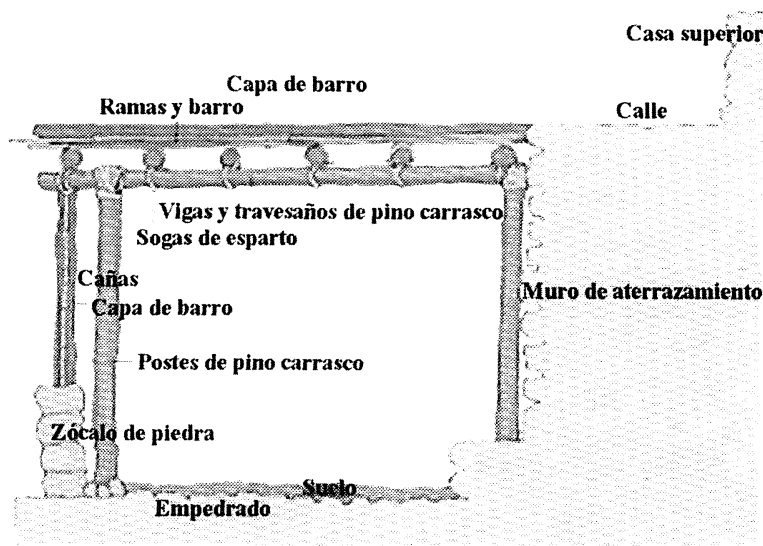

Fig. 4. CastellónAlto (Galera, Granada). Esquema de construcción de las viviendas.

yeso, sobre éste se ha añadido una mezcla de barro y resina sintética (Primal AC 33 al 5\%), tanto por el interior como por el exterior (Lam.V B), dejando un aspecto terroso, que se inserta totalmente en el entorno.

- Colocación de la cobertura vegetal. Para la reconstrucción del techo de la cabaña hemos utilizado principalmente cañas y anea, materiales que hemos obtenido en las inmediaciones del yacimiento, concretamente en la ribera del río Castilléjar y las acequias cercanas. Las cañas se han colocado de modo que cubrieran toda la superficie del armazón de vigas y travesaños, rellenando los huecos mayores con las aneas. La sujeción de esta cubierta al armazón de travesaños se ha realizado con cuerdas de esparto, formando una superficie lisa y ligeramente inclinada hacia el exterior (Lam. V B, fig. 4).

- Aislamiento de la cobertura. Se ha realizado en dos fases. En el mismo momento que se iban poniendo las cañas, éstas se cubrían con barro un poco líquido, con el fin de que entrará perfectamente por todos los huecos y trabará bien. En un segundo momento, la superficie de barro del techo se volvió cubrir con una mezcla de barro y resina sintética (Primal AC 33 al 5\%), que dió consistencia al barro y permitió su conservación ante agentes climáticos como la lluvia.

- Acondicionamiento del interior. En el interior de la vivienda se ha reconstruido un hogar y se rellenó de cenizas y carbones, con el aspecto de haber sido utilizado recientemente. También se ha puesto como puerta una estera de esparto realizada a base de pleitas, que ha sido confeccionada por artesanos locales.

- Reconstrucción de dos sepulturas. Se acon- dicionaron las sepulturas 18 y 19, que situadas en el corte 7 de la Ladera Oriental estaban realizadas en covachas en la pared posterior de las viviendas de esta zona (Lám. II A). La restauración, realizada en 1989, ha permitido que en ésta ocasión sólo hubiera que limpiar los restos de tierra acumulados durante estos años, sin tener que reparar sus paredes o estructuras.

Las réplicas de los restos óseos están realizadas en plástico (Somso-plast) por la casa comercial 3B de Alemania, que realiza modelos anatómicos de gran calidad. Estas réplicas han sido envejecidas con Betún de Judea hasta ofrecer un aspecto similar al de los restos antropológicos recuperados en las excavaciones.

En la sepultura 18 sólo se ha colocado el esqueleto del individuo en posición, de los dos individuos que se habían documentado en la excavación, junto a la réplica de un vaso globular que tenía como ajuar.

La sepultura 19 pertenecía a un individuo varón de 20-25 años de edad y $1,65 \mathrm{~m}$ de altura de complexión mediterránea robusta. Como ajuar ofrecía un cuenco carenado y un cuchillo junto al brazo derecho. También aparecieron restos de carne, documentados por un hueso de cabra. Este individuo presentaba la particularidad de tener la cabeza entre las manos fruto de una decapitación post-mortem. En la restitución, tanto del esqueleto, como del vaso carenado y cuchillo hemos intentado ser lo más fieles posibles a la posición original en que se encontraron los restos.

Una vez colocadas las réplicas óseas, cerámicas y metálicas las covachas han sido cerradas con cristales gruesos para permitir la visión del interior, pero a la vez servir de protección y evitar los hurtos (Lám. VII).

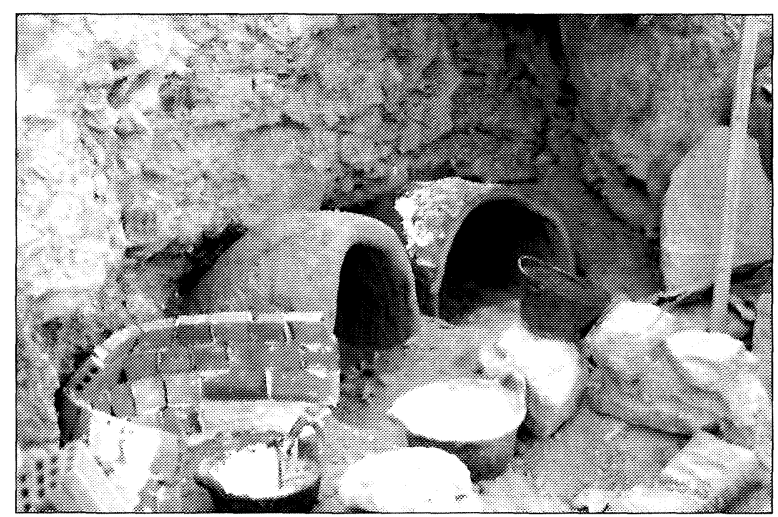

Lám. VI. CastellónAlto (Galera, Granada). Proceso de reconstrucción de las sepulturas de la Ladera Oriental. 


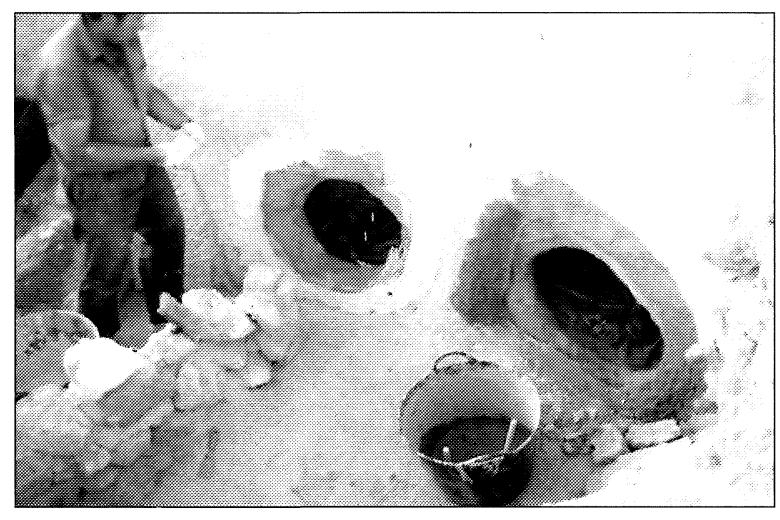

Lám. VII. Castellón Alto (Galera, Granada). Aspecto de las sepulturas 18 y 19 tras la colocación de las replicas óseas, cerámicas y metálicas.

\section{ESTADO ACTUAL Y PERSPECTIVAS}

Después de una década de intervenciones se pueden valorar no sólo los trabajos de conservación y restauración realizados en el propio yacimiento, sino también la incidencia que han tenido en la comarca y de las infraestructuras necesarias para que se cumpla el objetivo principal de contribuir a la difusión del patrimonio y enseñar historia.

En el Castellón Alto se realizó una importante inversión económica por parte de la Consejería de Cultura de la Junta de Andalucía para su restauración y acondicionamiento, pero posteriormente no ha sido asignada ninguna partida presupuestaria para el mantenimiento del mismo, ni por parte de la administración autonómica ni de la administración local. Salvo los trabajos de limpieza realizados en 1997, no se ha eliminado la vegetación ni atenuado los efectos de la erosión y del paso del tiempo. En este yacimiento las labores de mantenimiento y limpieza son sencillas siempre que se realicen periódicamente; es por ello que hay que destacar la importancia no sólo de poner en valor nuevos yacimientos, sino también de mantener los que ya tenemos.

Como se ha señalado anteriormente, uno de los principales problemas que ofrece este yacimiento arqueológico es el de la utilización de morteros que sean compatibles con la composición del suelo del lugar (gredas y yesos) y que soporten la enorme diferencia térmica existente, no sólo entre estaciones, sino entre el día y la noche, llegando a intervalos de más de $30^{\circ} \mathrm{C}$ en pocas horas. Los morteros con composición de gravas y arenas se han agrietado, resultando claramente incompatibles para el realzado de muros y estructuras arqueológicas. Sin embargo, la utilización de hormigón en las infraestructuras, como escaleras y pretiles, donde hay poco contacto con el subsuelo, ha sido positiva. El mortero realizado con tierra del lugar y resinas sintéticas cuando se ha utilizado encima de hormigón se ha desprendido, pero si ha resistido adecuadamente sobre las estructuras originales o sobre una base de yeso. Una de las observaciones que hemos realizado en el transcurso de estos últimos años es que aquellas estructuras o piedras que durante las campañas de excavación se cogieron con yeso presentan un aspecto y estabilidad inmejorables. Asimismo las paredes de la vivienda reconstruida del corte 13 , realizadas con cañas, yeso y una capa de tierra mezclada con resina sintética están en perfecto estado, tras años de su construcción. Por tanto, a la hora de proyectar futuras actuaciones el tema de los morteros habrá de ser estudiado en profundidad.

Para una adecuada interpretación y comprensión del yacimiento es necesario terminar de restaurar el área excavada del yacimiento, principalmente la Terraza Intermedia, pues la vivienda restaurada en 1997 queda aislada dentro del conjunto de estructuras arqueológicas. La restauración integral de este sector nos daría una visión de conjunto de un barrio del poblado, no sólo a nivel urbanístico y visual, sino que también nos permitiría reconstruir y explicar todas las actividades domésticas y artesanales que se desarrollaban, como la fabricación de útiles de piedra y hueso, la cestería o la actividad textil con la reconstrucción de un telar.

La existencia de un panel informativo a la entrada del yacimiento se muestra claramente insuficiente para explicar al visitante las características del asentamiento, por lo que se hace necesaria la instalación de paneles con planos y textos explicativos en cada zona del poblado. Igualmente, es obligado la señalización de los itinerarios de visita del yacimiento. Dentro de este apartado de infraestructuras de apoyo a la visita se está terminando de acondicionar una cueva, junto a la explanada del aparcamiento, que servirá como zona de acogida de los visitantes y lugar desde donde se inicie el recorrido.

En la base del yacimiento arqueológico hay una antigua mina de yeso que plantea una serie de posibilidades para complementar la visita al poblado prehistórico. En primer lugar es necesario la realización de un estudio sobre la resistencia del cerro y su nivel de estabilidad, para prevenir posibles

T. P., 57, n. $^{\circ} 2,2000$ 
desprendimientos de rocas. Por otra parte, la consolidación de la mina crearía un espacio donde se podría musealizar la actividad de fabricación del yeso, creándose un centro de interpretación sobre el entorno medioambiental del lugar, con una personalidad botánica, zoológica y geológica muy acusada, pues a la aridez de la zona se une la existencia de suelos yesosos y halófilos. Asimismo, la actividad agraria tradicional que aún se realiza en el valle del río podría ser estudiada, pues supone un inmejorable ejemplo de cómo las comunidades humanas se interrelacionan con el medio.

La visita al CastellónAlto tendrá como complemento indispensable la visita al Museo Arqueológico de Galera, actualmente en construcción, y que promovido por el Ayuntamiento de la localidad y con el apoyo del Plan Leader de la Zona Norte de Granada, la Consejería de Turismo de la Junta de Andalucía, la Fundación Caja Granada y la Consejería de Cultura de la Junta de Andalucía, servirá como centro de interpretación del rico patrimonio arqueológico del municipio, con yacimientos, junto al Castellón Alto, tan conocidos en la bibliografía arqueológica como el Cerro del Real (Pellicer y Schüle, 1962; 1966) y la necrópolis ibérica de Tútugi (Cabré y Motos, 1920). También será el centro desde donde se propondrán rutas y recorridos de especial interés arqueológico. En suma, el Museo de Galera se crea con voluntad de ser un centro cultural, científico y divulgativo de este importante legado arqueológico existente en el municipio y en la comarca de Huéscar.

\section{BIBLIOGRAFÍA}

CABré, J. y Motos, F. (1920): La Necrópolis ibérica de Tútugi (Galera, Provincia de Granada). Junta Superior de Excavaciones Arqueológicas, 25. Madrid.

Contreras, F.; Rodríguez-Ariza, Mão.; Cámara, J.A. y MoReno, A. (1997): Hace 4000 años... Vida y muerte en dos poblados de la Alta Andalucía. Catálogo de la exposición. Junta de Andalucía, Fundación Caja de Granada. Granada.

Molina, F.; Aguayo, P.; Fresneda, E. y Contreras, F. (1986): "Nuevas investigaciones en yacimientos de la Edad del Bronce en Granada". Homenaje a Luis Siret (1934-1984). Sevilla: 353-360.

Pellicer, M. y Schüle, W. (1962): Cerro del Real (Galera). Excavaciones Arqueológicas en España, 12, Madrid.

Pellicer, M. y Schüle, W. (1966): Excavaciones en el Cerro del Real (Galera, Granada). Excavaciones Arqueológicas en España, 52. Madrid.

RodrígueZ-ARIZA, Mª. y RuIZ SÁNCHEZ, V. (1995): “Antracología y palinología del yacimiento argárico de Castellón Alto (Galera, Granada)". Anuario Arqueológico de Andalucía 1992, II: 169-176. Cádiz.

Rodríguez-Ariza, MåO.; Ruiz SÁnchez, V.; Buxó, R. y Ros Mora, T. (1996): "Palaeobotany of a Bronze Age community. CastellónAlto (Galera, Granada, Spain)".Actes du Colloque d'Archéométrie 1995 de Périgueux, Revue d'Archéometrie, Suppl.: 191-196. Rennes. 